\title{
A robust nonlinear control strategy of a PV System connected to the three-phase grid based on backstepping and PSO technique
}

\author{
Salma Zouga ${ }^{1}$, Mohamed Benchagra ${ }^{2}$, Abdallah Ailane ${ }^{3}$ \\ ${ }^{1,3}$ National School of Applied Sciences, ISERT Laboratory, ENSA, Sultan Moulay Slimane Universiy, Khouribga, \\ Morocco \\ ${ }^{2}$ Superior School of Technology, EST-Benimellal, Sultan Moulay Slimane Universiy, Khouribga, Morocco
}

\section{Article Info}

Article history:

Received May 19, 2020

Revised Jan 28, 2021

Accepted Feb 13, 2021

\section{Keywords:}

Backstepping control Cascade regulation loops Lyapunov function control Optimized algorithm Three phase PV System

\begin{abstract}
This article presents a robust non-linear control technique of the three-phase photovoltaic system. The structure chosen for this PV system is that of two power converters and DC voltage intermediate bus. The two power converters are: the DC-DC converter and the three-phase inverter, which requires two main controllers. These controllers have three main objectives. The first objective is to impose the PV voltage generated by the photovoltaic panel, in order to follow a maximum reference voltage provided by the MPPT block. The second one is to maintain the DC link voltage to a constant value, in order to optimize the transfer of energy between the two power converters. The last objective is to inject a three-phase sinusoidal current into the grid, while respecting a unit power factor. With the intention to achieve these three objectives, we designed cascading nonlinear controllers by using the technique of non-linear backstepping control in the synthesis of these two controllers, based on the Lyapunov function, with regard to maximise the PVG output voltage, in order to have a unitary power factor at the grid side. In order to regulate DC-link voltage, we developed an integral proportional controller (PI) with parameters that are optimized by the Particle Swarm Optimization (PSO) method. The robustness of the controller designed approach is tested by a simulation in MATLAB/Simulink software, that improves the performances of each controller whatever conditions of climate.
\end{abstract}

This is an open access article under the CC BY-SA license.

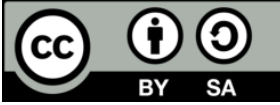

\section{Corresponding Author:}

Salma Zouga

National School of Applied Sciences

Sultan Moulay Slimane Universiy

927, AL Fath, Khouribga-Morocco

Email: zouga.selma@gmail.com

\section{INTRODUCTION}

During the last decade, we cannot imagine a single day without electricity. We consume more and more energy, and we want to produce it correctly. To meet this growing demand, we have been turning for the last few years towards clean and renewable energies, to produce more and more, without destroying the environment. Nowadays, more interest in photovoltaic energy (PV) has focused on photovoltaic systems connected to the grid [1]. However, the operation of these photovoltaic systems is influenced by the variation of weather conditions [2], the non-linearity of the switching functions of converters and inverters, and the load variation [3]. The impact of these different factors poses the control of these systems in front of the Different challenges to improve the performance and quality of the grid. Thus, it is essential to design robust controllers which ensure the main objectives of control represented by the correction of the power factor, regulation of the DC bus voltage and optimization of the power generated by the PV panel $[4,5]$. 
In the literature, many studies have focused on the design methods of linear controllers for photovoltaic systems connected to grid. Among these methods we can find: the classical PI controller generally used in industry, because it is cheap, robust, and it is easy to implement [6], it produces good results in linear systems. However, it has certain limitations, given thel uncertainties, and non-linear loads. In $[7,8]$, the control based on a PR controller, has also shown the good continuation of the reference, thanks to the infinite gain. Despite the usefulness of these linear controllers to achieve their objectives within a stable operating range, these linear methods become insufficient, and unreliable in the presence of rapidly changing operating conditions, including meteorological changes. For this reaon, the design of a control technique, adequate to perturbations, and to the non- linearity become necessary.

A lot of researches have proposed robust non-linear control methods to ensure stability [9-11], from PV systems connected to grid. The sliding mode controller (SMC) $[12,13]$, the predictive controller model [14], and the feedback linearization technique FBL [15], are mentioned. Each of its approaches has its own advantages, and disadvantages. The FBL technique offers the best performance over a wide range of operating ranges but it cancels the nonlinearities of the system and becomes a linear subsystem. In addition, this cancellation can be avoided by using a controller [16], based on the nonlinear Backstepping technique. This method will be presented in this paper, in order to design an appropriate control law, to ensure the overall stability of the system. Non-linear controller design, in cascade based on the Backstepping technique, takes into consideration the following control objectives: i) regulate the voltage which supplies the photovoltaic generator to extract the maximum power. ii) Phasing the voltages of the grid with the current by regulating this last, and to assert a perfect correction to the power factor (PFC). In order to keep the DC bus voltage at its desired reference value, a PI type controller based on a performing meta-heuristic algorithm "particle swarm optimization" (PSO) has been developed to optimize the Kp and Ki parameters of the controller. PSO is an optimization algorithm used in this paper to determine the parameters of the PI regulator in order to regulate the DC bus voltage. [17]. Compared with several methods, including genetic algorithms (GA), B-spline networks, fuzzy logic and neural networks [18], PSO has shown a better optimization, it is based on a simple algorithm characterized by ease of implementation and robustness. This paper is structured as follows: Section 2 presents the description of the system, and the mathematical model. Section 3 develops the nonlinear control strategies of the proposed system. Section 4 shows the simulation results as well as an analysis of these results. Finally, conclusion is giving in section 5.

\section{DESCRIPTION AND MODELLING OF THE STUDIED SYSTEM}

The following section presents the mathematical modeling of each component in the PV conversion chain. As illustrated in Figure1, the general structure of the system consists of two power stages to manage the PV power delivered to the utility grid. The first stage including a chopper that allows to extract the maximum power generated by the PV panel, by regulating the output capacitor's voltage to a constant value. Besides it allows to achieve the MPPT control by forcing the photovoltaic panel to operate at the optimum operating point despite the variation of environmental conditions. The second stage is represented by a threephase inverter whose main objective is to ensure the conversion of the DC power into an AC power injected into the grid, and controls the output current.

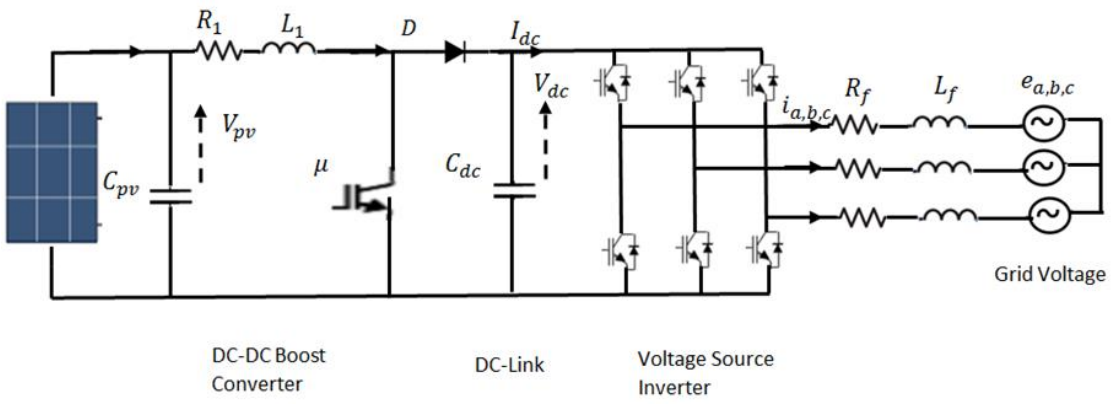

Figure 1. Structure of the grid-connected photovoltaic system

In order to have a zero phase shift with the voltage of the grid in order to obtain a unity FP. The use of the inductive filter $\mathrm{L}$ between the inverter and the three-phase grid is necessary, in order to minimize the harmonic components in the inverter output current generated by the PWM control. 
A photovoltaic panel consists of several cells associated in series and in parallel, which are electronic components that allow the transformation of light into electrical energy. The electrical characteristics of a single module used in this study are listed in Table 1. While the adopted mathematical model of a PV cell is shown in Figure 2, this model consists of a current generator $I_{0}$ controlled by voltage, and influenced by temperature and solar radiation, an anti-parallel diode D1, a shunt electrical resistance $R s h$, and a series resistance $R_{s}$ [19].

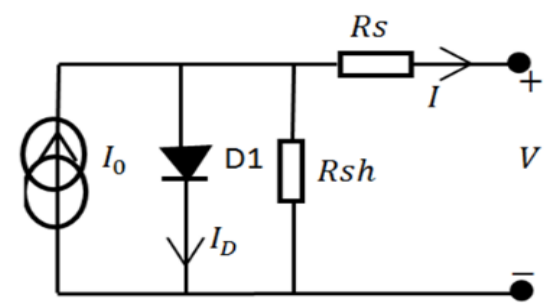

Figure 2. PV cell model

The relationship between PV current and PV output voltage is represented by the following mathematical equation:

$$
\mathrm{I}=\mathrm{I}_{0}-\mathrm{I}_{\mathrm{D}}\left[e^{q \frac{V+R_{S} I}{n K T_{K}}}-1\right]-\frac{V+I R_{S}}{R_{S h}}
$$

With I represent the light generated current, $I_{0}$ the diode saturation current, $T_{K}$ the temperature of cell, In $\mathrm{K}, \mathrm{n}$ the ideal factor, $\mathrm{q}$ the charge of an electron, in $\mathrm{C}$ and $\mathrm{K}$ the Boltzman's constant, in $\mathrm{J} / \mathrm{K}$

Table $1 \mathrm{PV}$ module parameters

\begin{tabular}{ll}
\hline \multicolumn{1}{c}{ Parameter } & \multicolumn{1}{c}{ Value } \\
\hline Maximum power & $260 \mathrm{~W}$ \\
Current at the maximum power point & $8,37 \mathrm{~A}$ \\
Voltage at the maximum power point & $31,1 \mathrm{~V}$ \\
Number of series modules & 6 \\
Number of parallel modules & 1 \\
\hline
\end{tabular}

The stabilization of the DC voltage $V_{D C}$ and the convergence of this voltage to its reference value is the objective of the developed control strategy. For this, obtaining a dynamic model of the DC/DC converter [20] is essential by using the kirchhoff law where the DC-link capacitor and the $C_{p v}$ capacitor are connected and this can be written as:

$$
\begin{aligned}
& \frac{d v_{p v}}{d t}=\frac{1}{C_{p v}}\left(i_{p v}-I_{L}\right) \\
& \frac{d i_{L}}{d t}=\frac{1}{L_{1}}\left[-R_{1} I_{L}+v_{p v}-(1-\mu) V_{d c}\right] \\
& \frac{d v_{d c}}{d t}=\frac{1}{C_{d c}}\left[(1-\mu)-I_{d c}\right]
\end{aligned}
$$

where $v_{p v}$ and $i_{p v}$ represent the generated PV output voltage and current, $V_{d c}$ designates the DC link voltage, $I_{L}$ and $I_{d c}$ are respectively the input and output current chopper, and $\mu$ is the duty cycle [21].

The second conversion stage represented by the three-phase inverter is used to generate the threephase currents injected into the grid. The inverter is based on PWM control and is connected to the grid through a bax pass filter. Whereas the dynamical model of voltage source inverter is expressed by the following equations $[22,23]$ : 


$$
\begin{aligned}
& L_{f} \frac{d i_{a}}{d t}=-R i_{a}-e_{a}+\frac{V_{d c}}{3}\left(2 S_{a}-S_{b}-S_{c}\right) \\
& L_{f} \frac{d i_{b}}{d t}=-R i_{b}-e_{b}+\frac{V_{d c}}{3}\left(-S_{a}+2 S_{b}-S_{c}\right) \\
& L_{f} \frac{d i_{c}}{d t}=-R i_{c}-e_{c}+\frac{V_{d c}}{3}\left(-S_{a}-S_{b}+2 S_{c}\right)
\end{aligned}
$$

The previous model is transformed into a new reference frame according to the angular frequency of the network, which allows us to rewrite the inverter model as follows:

$$
\begin{aligned}
& \frac{d I_{d}}{d t}=-\frac{R_{f}}{L_{f}} I_{d}+w I_{q}-\frac{1}{L_{f}} E_{d}+\frac{V_{d c}}{L} S_{d} \\
& \frac{d I_{q}}{d t}=-\frac{R_{f}}{L_{f}} I_{q}-w I_{d}-\frac{1}{L_{f}} E_{q}+\frac{V_{d c}}{L} S_{q}
\end{aligned}
$$

Id and Iq are are the active and reactive currents; Ed and Eq are are the active and reactive grid voltages; $\mathrm{Sd}$ and $\mathrm{Sq}$ are the switching control inputs.

\section{CONTROLLERS DESIGN STEPS}

In this section, we are interested in designing two robust controllers based on advanced mathematical algorithms dedicated to non-linear systems. The first controller concerns the PV voltage, it follows the maximum power point (MPPT) by two control loops, and regulates the voltage generated by the PV generator. For the second controller is based on two cascaded loops, an internal regulation loop to control the active and reactive power injected into the grid, and the external loop serves make the DC bus voltage stable according to the desired reference voltage. The full model of the design of these controllers is shown in the Figure 3, and it will be detailed in this section.

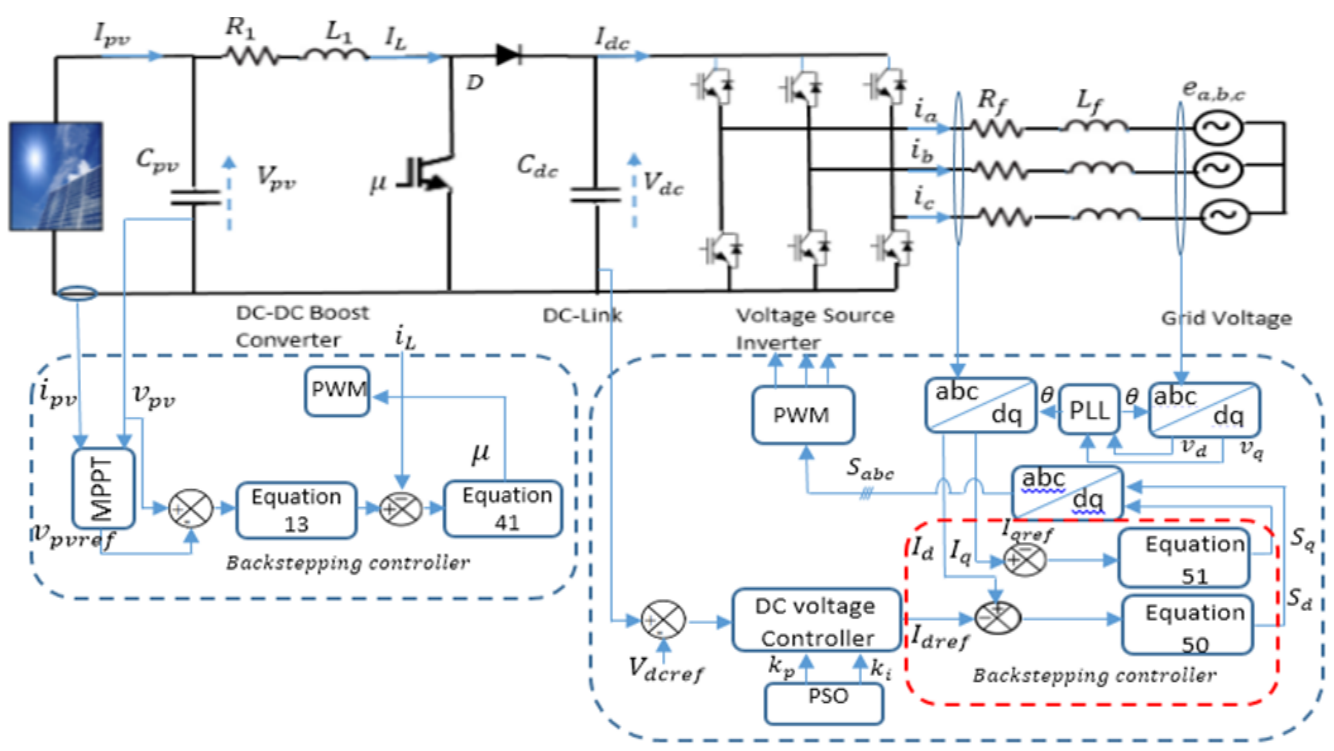

Figure 3. Nonlinear control scheme of the three-phase-grid connected photovoltaic system

\subsection{PV output voltage controller design}

The prinicipal goal of this regulator is to ensure the extraction of the maximum power generated by the PV panel whatever the operating conditions. For this reason, the design of this controller aims to stabilize the PV voltage at its reference value obtained by the MPPT algorithm based on incremental conductance technique. This regulation of the PV voltage is ensured by the Backstepping technique applied to the dynamics model (4), and based on the stabilization function of Lyapunov, the design of the controller is developed in two steps [24]. 

reference by:

In the first design step: we define the error between the voltage generated by the PV panel and its

$$
\mathrm{e}_{1}=\mathrm{V}_{\mathrm{pv}}-\mathrm{V}_{\mathrm{pvref}}
$$
voltage.

Where $V_{\text {pvref }}$ represents the voltage generated by the MPPT block which serves as a reference

By replacing with (4) the derivative of (10), results the error dynamics, which is:

$\dot{\mathrm{e}}_{1}=\frac{1}{\mathrm{C}_{\mathrm{pv}}}\left(\mathrm{i}_{\mathrm{pv}}-\mathrm{I}_{\mathrm{L}}\right)-\dot{\mathrm{V}}_{\mathrm{pvref}}$

To confirm the stability, Lyapunov candidate function (CLF) is calculated as:

$\mathrm{V}_{1}=\frac{1}{2} \mathrm{e}_{1}{ }^{2}$

Its time derivative is given as follows:

$\dot{\mathrm{V}}_{1}=\mathrm{e}_{1} \dot{\mathrm{e}}_{1}$

If we consider $\dot{e}_{1}=-k_{1} e_{1}$ the derivative of CLF can be written as:

$\dot{\mathrm{V}}_{1}=-\mathrm{k}_{1} \mathrm{e}_{1}{ }^{2}$

Making $\dot{V}$ negatively defined definite $\left(\dot{V}_{1}<0\right)$ or semi-definite $\left(\dot{V}_{1} \leq 0\right)$ allows to stabilize $\dot{e}_{1}$ and to have a null convergence error. which makes it possible to write $\dot{V}_{1}$ in a simplified form:

$$
\dot{\mathrm{V}}_{1}=\frac{1}{\mathrm{C}_{\mathrm{pv}}}\left(\mathrm{i}_{\mathrm{pv}}-\mathrm{I}_{\mathrm{L}}\right)-\dot{\mathrm{V}}_{\mathrm{pvref}}=-\mathrm{k}_{1} \mathrm{e}_{1}
$$

If we choose $I_{L}$ as virtual control input, we deduce the stabilizing function $\left(\alpha=I_{L r e f}\right)$, which ensure the asymptotic stability of the subsystem (17). And from (27) the desired value of the first virtual control can be written as follows:

$$
\alpha=\mathrm{i}_{\mathrm{pv}}-\mathrm{C}_{\mathrm{pv}}\left(\mathrm{V}_{\mathrm{pvref}}-\mathrm{k}_{1} \mathrm{e}_{1}\right)
$$

As $I_{L}$ is not the final control input, and not always equal to the stabilizing function, in the following a new error variable $e_{2}$ between the virtual control $I_{L}$ and its desired value $\alpha$ is introduced step to define the final control input signal.

In the second design step: we define the error between the current and its reference value $\alpha$ as:

$$
\mathrm{e}_{2}=\mathrm{I}_{\mathrm{L}}-\alpha
$$

Whose dynamics is based on the subsystem (18) and it can be expressed by:

$$
\dot{\mathrm{e}}_{2}=\frac{1}{\mathrm{~L}}\left[\mathrm{v}_{\mathrm{pv}}-(1-\mu) \mathrm{V}_{\mathrm{dc}}-\mathrm{R}_{1} \mathrm{I}_{\mathrm{L}}\right]-\dot{\alpha}
$$

In contemplation of stabilizing the subsystems (4) and (5), we consider the second candidate Lyapunov function:

$$
\mathrm{V}_{2}=\mathrm{V}_{1}+\frac{1}{2} \mathrm{e}_{2}{ }^{2}
$$

Before obtaining the derivation of the Lyapunov candidate Function $V_{2}$, it is necessary to simplify the value of the derivative of $\dot{V}_{1}$ represented by (15). For this, the dynamics of the error $e_{1}$ can be reexpressed by: 


$$
\dot{\mathrm{e}}_{1}=\frac{1}{\mathrm{C}_{\mathrm{pv}}} \dot{\mathrm{i}}_{\mathrm{pv}}-\frac{\mathrm{e}_{2}}{\mathrm{C}_{\mathrm{pv}}}-\frac{\alpha}{\mathrm{C}_{\mathrm{pv}}}-\dot{\mathrm{V}}_{\mathrm{pvref}}
$$
follows:

From (13), (16) and (20) the dynamics of tracking error $e_{1}$ and Lyapunov function can be written as

$$
\begin{aligned}
& \dot{\mathrm{e}}_{1}=-\mathrm{k}_{1} \mathrm{e}_{1}-\frac{\mathrm{e}_{2}}{\mathrm{C}_{\mathrm{pv}}} \\
& \dot{\mathrm{V}}_{1}=-\mathrm{k}_{1} \mathrm{e}_{1}{ }^{2}-\frac{\mathrm{e}_{1} \mathrm{e}_{2}}{\mathrm{C}_{\mathrm{pv}}}
\end{aligned}
$$

The time derivative of $V_{2}$ is given by using the (19) and value of $\dot{V}_{1}$,

$\dot{\mathrm{V}}_{2}=-\mathrm{K}_{1} \mathrm{e}_{1}^{2}+\mathrm{e}_{2}\left(\dot{\mathrm{e}}_{2}-\frac{\mathrm{e}_{1}}{\mathrm{C}_{\mathrm{pv}}}\right)$

If we set $V_{2}<0$ or $V_{2} \leq 0$, we can ensure the stability of the error derivative $e_{2}$, and we can put:

$-K_{2} e_{2}=\dot{e}_{2}-\frac{e_{1}}{C_{p v}}$ becomes:

Where, $K_{2}$ is a real positive design parameter, and the dynamics of the Lyapunov candidate function

$$
\dot{\mathrm{V}}_{2}=-\mathrm{K}_{1} \mathrm{e}_{1}{ }^{2}-\mathrm{K}_{2} \mathrm{e}_{2}{ }^{2} \leq 0
$$

The equations (24) and (18) lead to:

$$
-\mathrm{K}_{2} \mathrm{e}_{2}=\frac{1}{\mathrm{~L}}\left[\mathrm{v}_{\mathrm{pv}}-(1-\mu) \mathrm{V}_{\mathrm{dc}}-\mathrm{R}_{1} \mathrm{I}_{\mathrm{L}}\right]-\dot{\alpha}-\frac{e_{1}}{C_{p v}}
$$

By replacing (26) in the expression of the dynamics of CFL (25), we get the real control input signal noted $\mu$, that ensures the stability of the system $\left(\mathrm{e}_{1}, \mathrm{e}_{2}\right)$ :

$$
\mu=1-\frac{1}{V_{d c}}\left(-R_{1} I_{L}+v_{p v}+L_{2} e_{2}-L \dot{\alpha}-\frac{L_{1}}{C_{p v}}\right)
$$

\subsection{Active and reactive power controller design}

The objective of this controller is to achieve a unity power factor by regulation of the direct and quadratic component of the current $I_{d}, I_{q}$ to be sinusoidal and in phase with the grid supply voltage. This internal current regulation loop aims to make the current $I_{d}$ and $I_{q}$ present adequate values with its generated reference values, in order to inject an optimal active power and zero reactive power.

The initial step of this controller is to define the tracking error between the active current and its reference value by:

$$
e_{3}=I_{d}-I_{d r e f}
$$

Where the reference current $I_{d r e f}$ is generated by the external voltage regulation loop discussed in the following section, and which is expressed as follow:

$$
I_{\text {dref }}=\beta E_{d}
$$

With $\beta$ is any positive real constant generated by the outer voltage loop.

The time derivative of the tracking error between the active current and its reference value $e_{3}$, is expressed by:

$$
\dot{\mathrm{e}}_{3}=-\frac{\mathrm{R}_{\mathrm{f}}}{\mathrm{L}_{\mathrm{f}}} \mathrm{I}_{\mathrm{d}}+\mathrm{wI} \mathrm{I}_{\mathrm{q}}-\frac{1}{\mathrm{~L}_{\mathrm{f}}} \mathrm{E}_{\mathrm{d}}+\frac{\mathrm{V}_{\mathrm{dc}}}{\mathrm{L}_{\mathrm{f}}} \mathrm{S}_{\mathrm{d}}-\dot{\mathrm{I}}_{\mathrm{dref}}
$$


Alternatively, we defined the tracking error between the reactive current and its reference value error as:

$\mathrm{e}_{4}=\mathrm{I}_{\mathrm{q}}-\mathrm{I}_{\mathrm{qref}}$

Using the value of $\dot{I}_{q}$, we can express the derivative of $e_{4}$ by:

$\dot{\mathrm{e}}_{4}=-\frac{\mathrm{R}_{\mathrm{f}}}{\mathrm{L}_{\mathrm{f}}} \mathrm{I}_{\mathrm{q}}-\mathrm{wI}_{\mathrm{d}}-\frac{1}{\mathrm{~L}_{\mathrm{f}}} \mathrm{E}_{\mathrm{q}}+\frac{\mathrm{v}_{\mathrm{dc}}}{\mathrm{L}_{\mathrm{f}}} \mathrm{S}_{\mathrm{q}}-\dot{\mathrm{I}}_{\mathrm{qref}}$

The determination of the conditions on the control law requires the choice of the Lyapunov stability function which allows to find the balancing point of the system. Thus, a new CLF is being considered which makes it possible to deduce the control signals $S_{d}$ and $S_{q}$

$$
\mathrm{V}_{3}=\mathrm{V}_{2}+\frac{1}{2} \mathrm{e}_{3}^{2}+\frac{1}{2} \mathrm{e}_{4}^{2}
$$

The derivative of this CLF is represented by:

$$
\dot{\mathrm{V}}_{3}=\dot{\mathrm{V}}_{2}+\mathrm{e}_{3} \dot{\mathrm{e}}_{3}+\mathrm{e}_{4} \dot{\mathrm{e}}_{4}
$$

By replacing the values of $\dot{V}_{2}$ from (25), $\dot{\mathrm{e}}_{3}$ from (30), and $\dot{\mathrm{e}}_{4}$ from (32) into (34) yields we've got:

$$
\begin{aligned}
& \dot{\mathrm{V}}_{3}=-\mathrm{K}_{1} \mathrm{e}_{1}{ }^{2}-\mathrm{K}_{2} \mathrm{e}_{2}{ }^{2}+\mathrm{e}_{3}\left(\frac{\mathrm{R}_{\mathrm{f}}}{\mathrm{L}_{\mathrm{f}}} \mathrm{I}_{\mathrm{d}}+\mathrm{wI}_{\mathrm{q}}-\frac{1}{\mathrm{~L}_{\mathrm{f}}}\left(\mathrm{E}_{\mathrm{d}}-\mathrm{V}_{\mathrm{dc}} \mathrm{S}_{\mathrm{d}}\right)-\dot{\mathrm{I}}_{\mathrm{dref}}\right)+\mathrm{e}_{4}\left(\frac{\mathrm{R}_{\mathrm{f}}}{\mathrm{L}_{\mathrm{f}}} \mathrm{I}_{\mathrm{q}}-\mathrm{wI}_{\mathrm{d}}-\right. \\
& \left.\frac{1}{\mathrm{~L}_{\mathrm{f}}}\left(\mathrm{E}_{\mathrm{d}}-\mathrm{V}_{\mathrm{dc}} \mathrm{S}_{\mathrm{q}}\right)-\dot{\mathrm{I}}_{\mathrm{qref}}\right)
\end{aligned}
$$

to make the derivative of $\mathrm{V}_{3}$ negatively defined allows us to have a global stability of the system, and this by choosing the following switching control laws:

$$
\begin{gathered}
S_{d}=\frac{L_{f}}{V_{d c}}\left(\frac{R_{f}}{L_{f}} I_{d}-w I_{q}+\dot{I}_{d r e f}-k_{3} e_{3}+\frac{E_{d}}{L_{f}}\right) \\
S_{q}=\frac{L_{f}}{V_{d c}}\left(\frac{R_{f}}{L_{f}} I_{q}+w I_{q}+\dot{I}_{\text {qref }}-k_{4} e_{4}+\frac{E_{q}}{L_{f}}\right)
\end{gathered}
$$

By using a derivative of the CLF, we can simplify the equation (35) as:

$$
\dot{V}_{3}=-K_{1} e_{1}^{2}-K_{2} e_{2}^{2}-k_{3} e_{3}^{2}-k_{4} e_{4}^{2} \leq 0
$$

This ensures a general stabilization related to the dynamic operation of the VSI, and which makes it possible to inject an optimal value of the active power and a zero injection of the reactive power.

\subsection{Design of DC-link voltage controller}

The DC bus voltage control loop must ensure two control objectives the first is to keep this voltage stable, and the second is to generate the active reference current. required for the internal current loop.

Therefore, the design of this controller based on a PI voltage loop, which has as inputs: the squared of the DC bus voltage $V_{d c}{ }^{2}$ and its reference component $V_{d c r e f}{ }^{2}$, and which generates at its output a control signal $\beta$ multiplied by grid voltage to determine the amplitude of the current injected into the grid. The block diagram of the control loop is shown in Figure 4.

In closed loop, the tuning law $\beta$ is expressed by

$$
\beta=\left(V_{d c r e f}^{2}-V_{d c}^{2}\right) \cdot F(s)
$$

$F(s)$ is the transfer function of conventional PI controller, expressed by: $k_{p}+k_{i} *\left(\frac{1}{s}\right)$.

The determination of the control parameters $k_{i}$ and $k_{p}$ must be precise in order to ensure the optimal stability point and a slower dynamic compared to the internal current loops, for this purpose the Particle Swarm Optimization (PSO) control technique has been adopted which has become one of the favorites in optimization algorithms solutions, thanks to its simplicity of implementation, its robustness and its capacity 
to improve proportional integral (PI) performances, by searching for the best values in order to make the error as small as possible or zero.

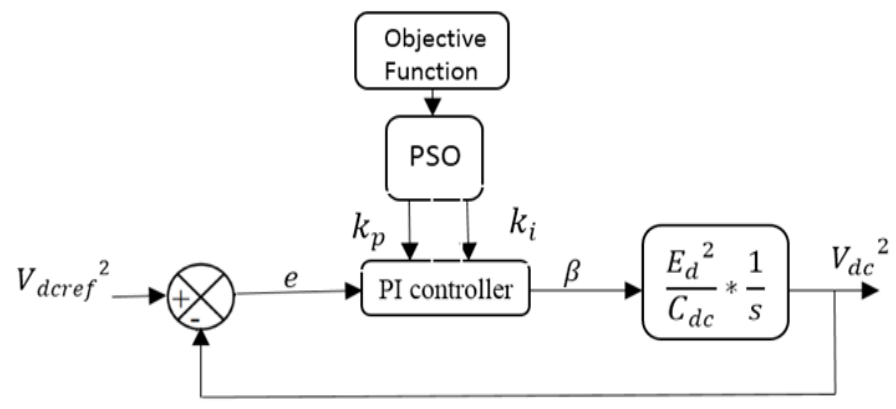

Figure 4. PSO algorithm based DC-link Voltage control loop

\subsubsection{Particle swarm optimization algorithm}

The PSO algorithm is considered one of the most excellent optimization methods that have undergone many changes since its introduction in 1995, by Kennedy and Eberhart. PSO has proven robust in solving continuous nonlinear optimization problems, its principle adopts a conventional swarm management for birds. Each "bird" is represented by a particle. and represents a candidate solution to the optimization problem. A swarm includes of S-particles flowing through a multidimensional search space, and each of its particles adjust its position in search space according to its own experience and that of neighbouring particles. Thus, a particle uses the good position encountered by itself and that of its neighbours particles to position itself towards the most optimal solution. The second essential factor in this technique and which allows each particle to change its position is the velocity information, which allows each particle during updating process at every iteration to find its best and only solution.

every particle is represented as a point in a j-dimensional space. The ith particle is represented as $X_{i}=\left(x_{i 1}, x_{i 2}, \ldots, x_{i j}\right)$. The best previous position of ith particle swarm is represented as $P_{i}=$ $\left(p_{i 1}, p_{i 2}, \ldots, p_{i j}\right)$, this is called pbest. Thus, a particle uses the good position encountered by itself and that of its neighbours particles to position itself towards the most optimal solution. The second essential factor in this technique and which allows each particle to change.

$$
V_{i j}^{n+1}=w * V_{i j}^{n}+r_{1} c_{1}\left(P_{i j}{ }^{n}-X_{i j}{ }^{n}\right)+r_{2} c_{2}\left(P_{g j}{ }^{n}-X_{i j}{ }^{n}\right)
$$

Where $w$ is the inertia weight, $c_{1}$ and $c_{2}$ are acceleration coefficients, $r_{1}$ and $r_{2}$ are random numbers uniformly distributed between 0 and 1 , and $n$ represents the iteration number.

The new position of the particles is obtained on the basis of its velocity and its previous position:

$$
X_{i j}^{n+1}=X_{i j}^{n}+V_{i j}^{n+1}
$$

The performance of each particle is measured using a predefined objective (fitness) function, which define the characteristics of the optimization problem [25].

\subsubsection{PI controller based on PSO technique}

In this work, the PSO algorithm is used to determine the optimal values of $k_{i}$ and $k_{p}$ of the PI controller. The implementation structure of the PSO technique for tuning the PI controller in the DC bus control loop is represented in Figure 4, its performance evaluation based on the objective function defined by the minimum time multiply squared error ITSE, and which can be represented by:

$$
\operatorname{ITSE}=\int_{0}^{\infty} \mathrm{t} \cdot \mathrm{e}^{2} \mathrm{dt}
$$

Where $e$ is the PI controller input that expressed the error between the square of the measured voltage $V_{d c}$ and the square of its reference value $V_{d c r e f}$. 


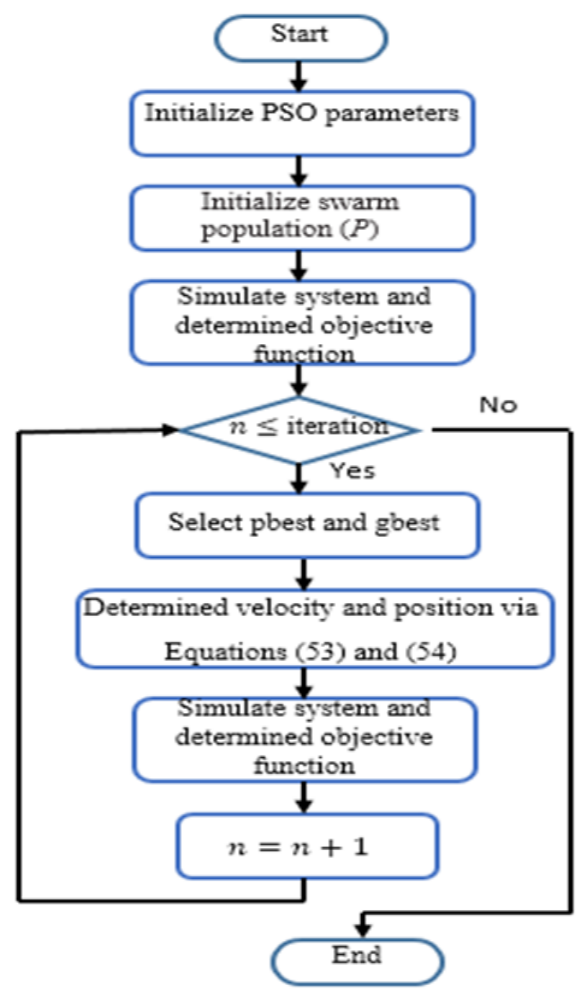

Figure 5. implementation algorithm of the PSO-PI controller method

The computational flowchart in Figure 5 represents the algorithm used in the implementation of the PSO for the purpose of optimizing the parameters of the PI. The Parameters initialization at the beginning of the PSO algorithm includes the maximum number of iterations $n$ that is equal to 100 iterations, the size of the population $i$ that is considered by 30 individuals (particles) in the population, as well as the acceleration coefficients $c_{1}$ and $c_{2}$ and the inertia weight $w$. Since the dimension of the problem concerns two parameters $k_{i}$ and $k_{p}$ to be controlled, the position and the velocity are represented by matrices with the dimension of $2 \times 30$ by using the (40) and (41). At the end of the algorithm the best position of a particle represents the optimal values of the controller gains $k_{i}$ and $k_{p}$.

\section{RESULTS AND ANALYSIS}

Simulations are done in MATLAB/Simulink software in order to verify and evaluate the performance of the nonlinear controller based on the Backstepping technique, designed in the above section and illustrated in Figure 3. The global parameters are obtained on the basis of the theoretical study shown in the design part of the controller and that are given in Table 2, The simulation results were generated under stable operating conditions which are $:\left(\mathrm{G}=1000 \mathrm{w} / \mathrm{m}^{2}, \mathrm{~T}=25^{\circ} \mathrm{C}\right)$, and other different conditions.

Table 2. parameters of the proposed PV system

\begin{tabular}{lcc}
\hline \multicolumn{1}{c}{ Parameter } & Symbol & Value \\
\hline PV-array power & $\mathrm{P}_{\mathrm{pv}}$ & $1562 \mathrm{~W}$ \\
DC bus capacitor & $\mathrm{C}_{\mathrm{dc}}$ & $3 \times 10^{3} \mu \mathrm{F}$ \\
Switching frequency & $\mathrm{F}_{\mathrm{s}}$ & $5 \mathrm{KHz}$ \\
Grid & $\mathrm{V}_{\mathrm{g}}$ & $380 \mathrm{~V} / 50 \mathrm{~Hz}$ \\
Filter parameters & $\mathrm{L}$ & $1,8 \mathrm{mH}$ \\
& $\mathrm{R}$ & $0,05 \Omega$ \\
PV voltage regulator & $\mathrm{k}_{1}$ & $3 \times 10^{-2}$ \\
& $\mathrm{k}_{2}$ & $5 \times 10^{-3}$ \\
Current regulator & $\mathrm{k}_{3}$ & $10^{7}$ \\
& $\mathrm{k}_{4}$ & \multicolumn{2}{c}{} \\
PI-PSO & $\mathrm{k}_{\mathrm{i}}$ & 0.8 \\
\hline
\end{tabular}




\section{Case 1: (Simulation under constant irradiance and temperature)}

The Figure 6-10 illustrate the behavior of the main system singals after a simulation under stable conditions $\left(G=1000 \mathrm{w} / \mathrm{m}^{2} ; T=25^{\circ} \mathrm{C}\right)$, in order to demonstrate the most significant aspects of the control strategy proposed.

Figure 6 shows the behavior of the voltage generated by the PV array, which follows its reference value at nearly $93.3 \mathrm{~V}$ thanks to the hybrid Mppt command that introduces both techniques (Inccond and Backstepping). The values of the current and the input voltage of the choppers indicate respectively, $16.74 \mathrm{~A}$ and $93.3 \mathrm{~V}$, and the value of the PV power is about $1561.8 \mathrm{~W}$. This justifies the reliability of the external voltage controller based on the lyapunov function which has ensured a global stabilization of the system, and makes it possible to extract the instantaneous voltage and maximum current generated by the PV generator.

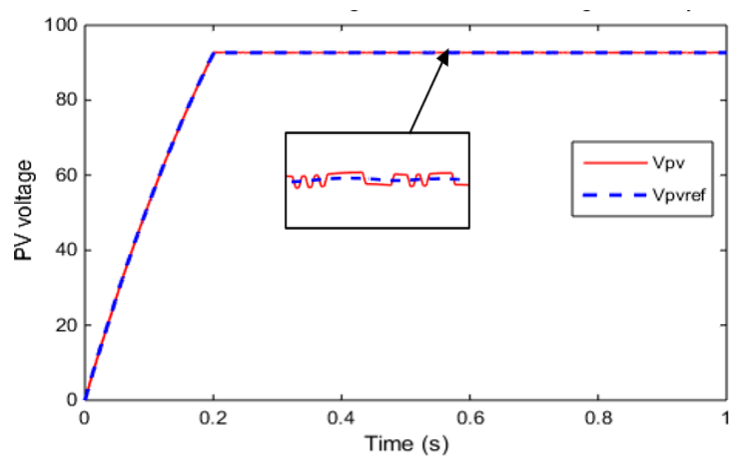

Figure 6. Input Voltage $V_{p v}$

Figure 7 represents the behavior of the output voltage of the chopper, as can be noticed in this figure the voltage follows perfectly (on average) its reference value (360), which proves the performance of the DC bus voltage regulation loop, that introduces the PSO based PI dc link controller, with the ability to quickly and accurately converge to its reference values.

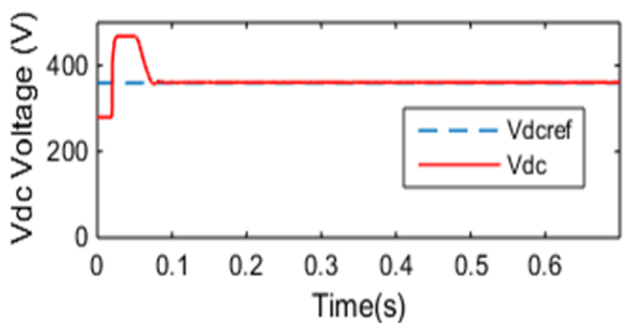

Figure 7. DC -bus voltage

Figure 8 shows the output current and the AC voltage waveforms, from this figure, we note that there is a zero phase difference between the voltage and the injected current., which makes it possible to have the unity power factor is well achieved and the frequency remained constant and equal to the grid-voltage frequency. Moreover, the current injected into the network converges to its reference value after a short transient phase $(0.07 \mathrm{~s})$ which means that the nonlinear current controller developed has given us the expected results and the control that we have set up allows us to have a unit power factor. And according to figure 9 , we notice that the reactive power is regulated to zero and the active power injected into the grid reaches its maximum value $(1562 \mathrm{~W})$, which will ensure a total transfer of $\mathrm{PV}$ power.

The improvement of the quality of the injected power is ensured by the non-linear control loops, which is proved by Figure 10 which show the THD in the current, as it can be noticed that the THD in the grid current is 3,34 which is under the standard value required not to exceed $5 \%$. 


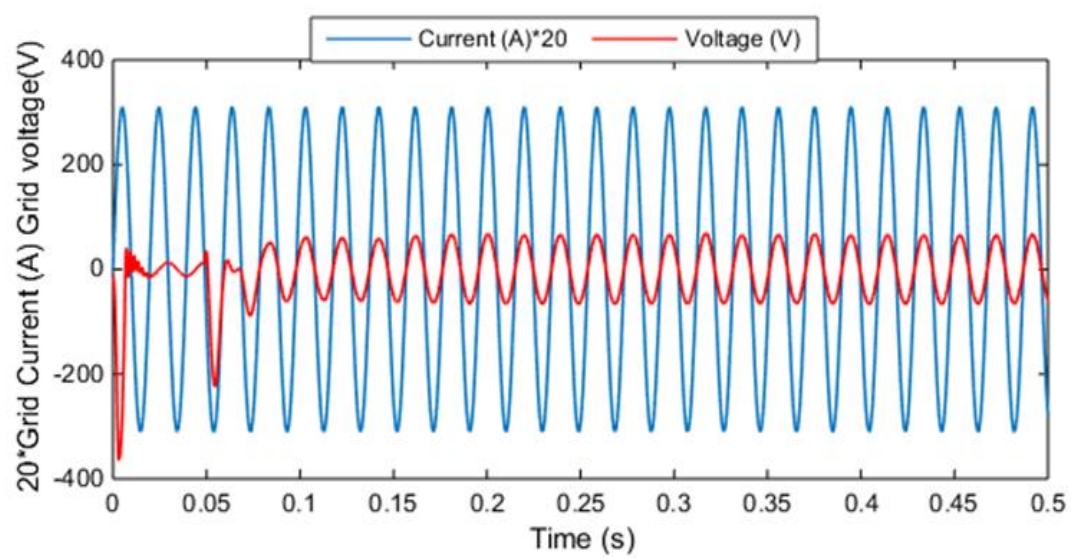

Figure 8. Injected phase voltage and current

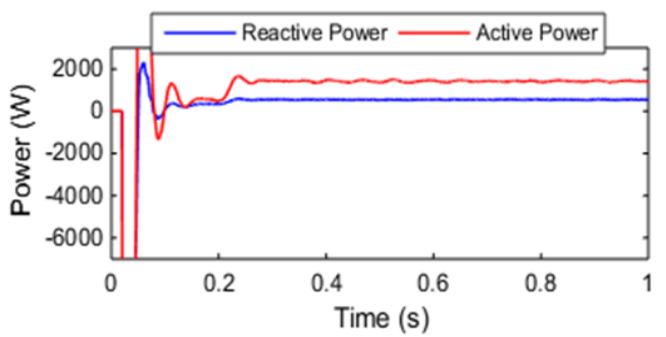

Figure 9. Active and reactive grid power

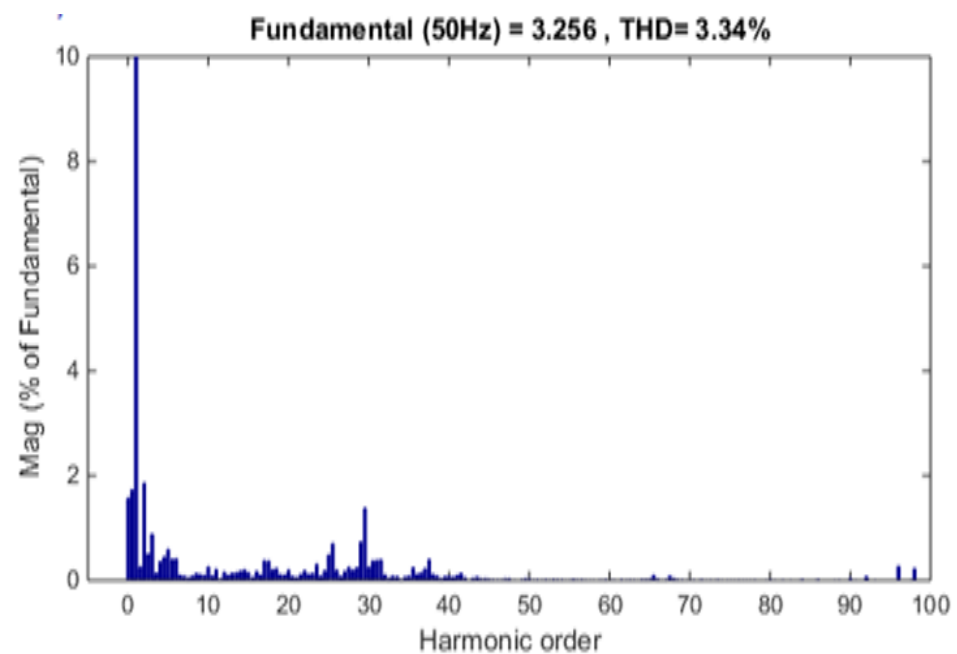

Figure 10. Frequency analysis of the current injected into the grid

\section{Case 2: Simulation under irradiation variations}

The PV system operates under an unstable irradiance level, which causes variations in the generated PV power. In this second simulation step, the robustness of the non-linear cascade controllers based on the backstraping-PSO technique is tested under variable radiation and a constant temperature equal to $25^{\circ} \mathrm{C}$. according to figure 11 the solar irradiation suddenly drops from $1000 \mathrm{~W} / \mathrm{m} 2$ to $700 \mathrm{~W} / \mathrm{m} 2$ at $0.7 \mathrm{~s}$ and continues to maintain this irradiation level till $1.5 \mathrm{~s}$. then it returns to its level $1000 \mathrm{~W} / \mathrm{m} 2$ after $1.5 \mathrm{~s}$. Figure 12 represents the behavior of the voltage generated by the PV panel, which perfectly follows its reference value generated by the MPPT block, thanks to the external voltage control loop. with a small decrease in the output voltage $(91 \mathrm{~V})$ during the change of irradiation between $0.7 \mathrm{~s}$ and $1.5 \mathrm{~s}$. 


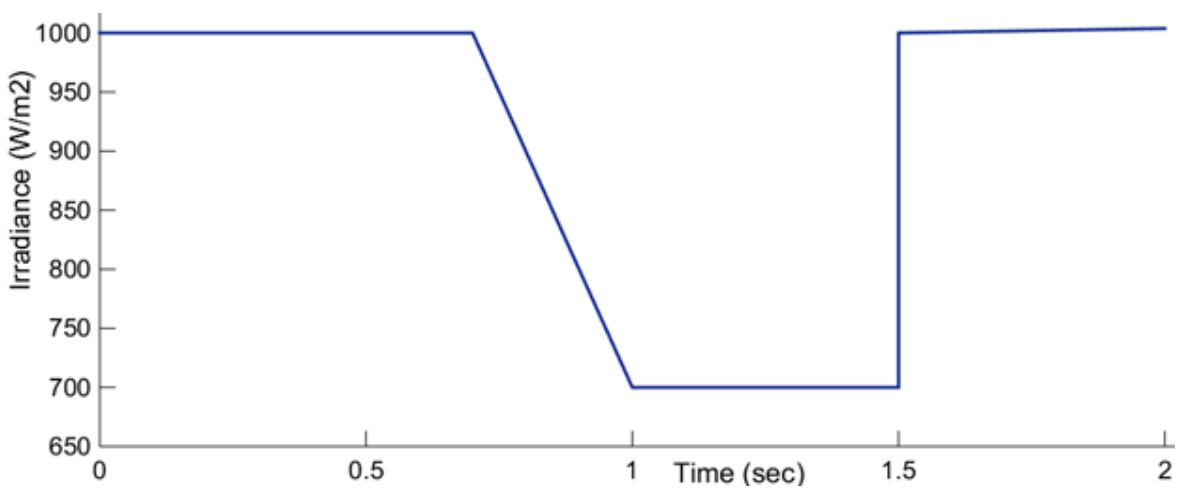

Figure 11. Solar irradiance changes

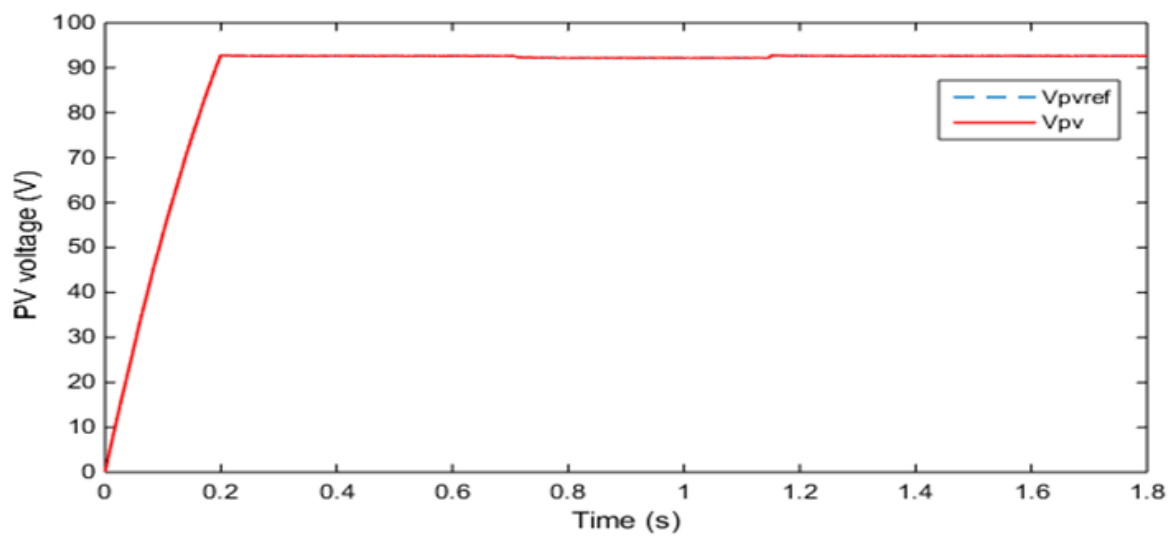

Figure 12. PV voltage

Figure 13 indicates the behaviour of the DC bus voltage that remains constant and follows its reference value, which is equal to $360 \mathrm{~V}$, this voltage presents rapid transitions after each change in irradiance value. Also, on the instants $0.7 \mathrm{~s}$ and $1.5 \mathrm{~s}$, the voltage is changed but it is returned to its value after a short transient period. Which confirms the high precision of the PI controller parameters ki and kp generated by the PSO algorithm.

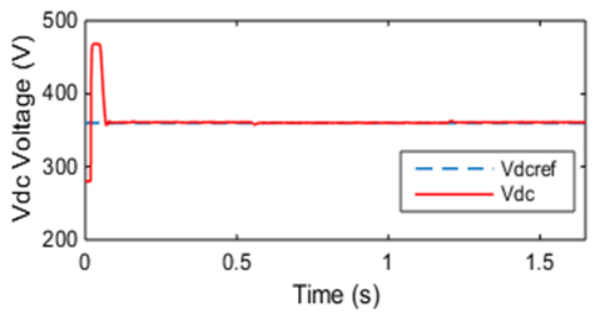

Figure 13. DC link voltage

Figure 14 shows the behavior of the active and reactive current during changes in irradiance. It can be deduced that, despite the sudden large change in irradiance, the current inner loop based on the backstepping technique has shown robust and accurate performance in the monitoring of the two references current signals idref and iqref. In addition, the precise choice of the stabilization parameters K1 and K2 provided rapid and precise response. 


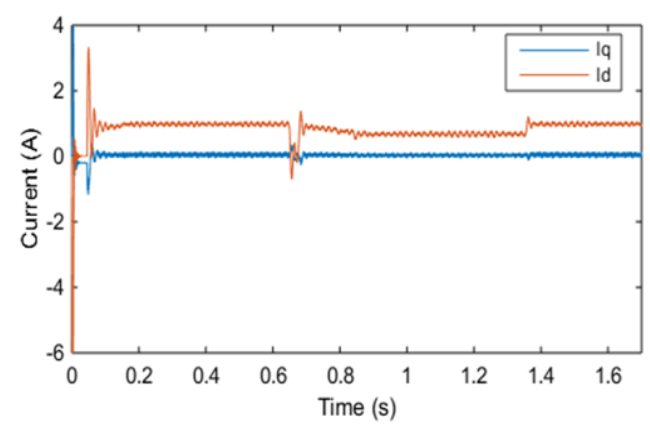

Figure 14. Current components behavior

Figure 15 presents the behavior of voltage and current injected during irradiance variations (the amplitude of the current is multiplied by 20 compared to its actual value in order to draw the two curves in the same graph). at $0.6 \mathrm{~s}$ the amplitude of the injected current is reduced due to the reduction of the power generated, however there is a zero phase shift between current and voltage during each instant which confirms the validity of the proposed non-linear controller, high quality of the injected current to network and obtaining a unit power factor during changes in irradiance. Finally, Figure 16 illustrates the behavior of the active and reactive power during the irradiance changes occur in the system, the active power injected into the grid which has decreased from $1500 \mathrm{~W}$ to $900 \mathrm{~W}$ in accordance with the variation in irradiance which also decreased from $1000 \mathrm{~W} / \mathrm{m} 2$ to $700 \mathrm{~W} / \mathrm{m} 2$. However, the injected active power corresponds well to the maximum power produced by the PV panel while the reactive power injected kept at zero.

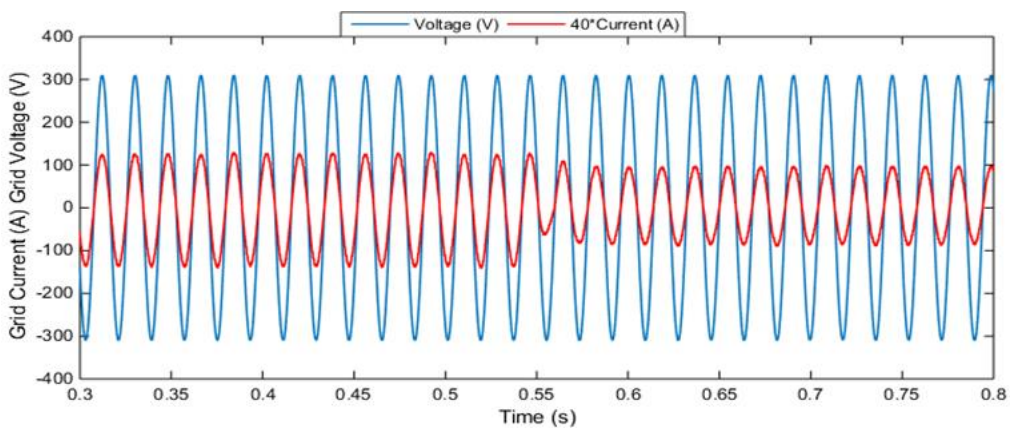

Figure 15. Injected phase voltage and current

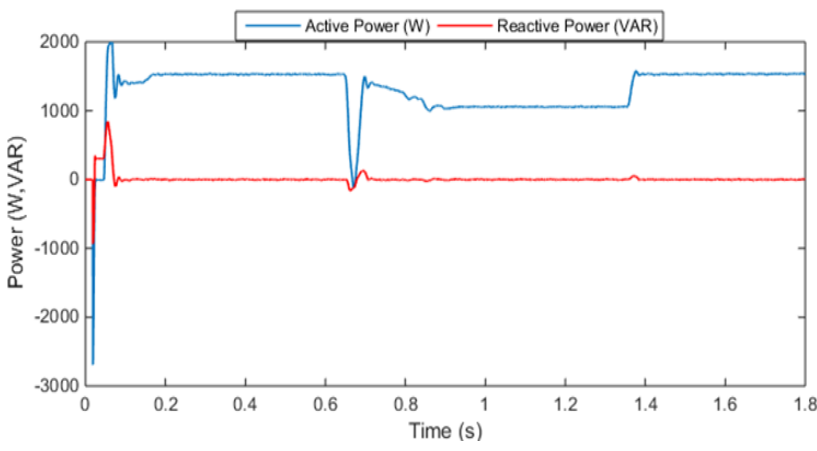

Figure 16. Active and reactive grid power

The analysis of the simulation results obtained, allows us to deduce that the proposed control strategy in this article presents improved performances during all cases of operation. Thanks, of the internal current loops and the PV generator voltage loop based on the Backstepping technique, we were able to have a 
quick and precise regulation of the PV voltage, which ensured maximum extraction of the PV power generated. on the other hand, they have improved both the active power and the reactive power of the electric grid as well as the quality of the current injected into the grid, whose harmonic rate is low compared to other control methods [26]-[27]. Moreover, the optimization of the IP parameters based on the PSO algorithm has reacted quickly, so that the DC bus voltage can reach its reference and quickly eliminates the tracking in order to achieve overall stability.

\section{CONCLUSION}

This paper has presented a robust nonlinear control strategy for three-phase PV system connected to grid. The controllers design for this command combines the backstepping-based control method and the PI controller based on the PSO algorithm. After a mathematical description of the overall model-based system (19-23), stability analysis was performed using the advanced mathematical tool represented by Lyapunov stability. Based on the theoretical study and simulation of the system under MATLAB/Simulink, the results obtained showed importance and satisfaction. More precisely, it is demonstrated that all the control objectives are achieved, including precise PV voltage regulation with zero tracking error, requirement of PFC, keep the system in optimal performance in spite of variations in climatic conditions, and regulation of the DC-bus voltage, which has shown an improvement response in terms of response time and overshoot.

The choice of the controllers gains for the non-Linear Backstepping control strategy, is an important and difficult task because of its impact on performance, and the stability of the overall system. For this reason, the contribution of this paper lies in the introduction of the PSO technique to adapt the gains of the DC bus voltage controller with those of the Backstepping, to ensure overall stability and to obtain improved results compared to other control methods.

\section{REFERENCES}

[1] S. Kouro, et al., "Grid connected photovoltaic systems: An overview of recent research and emerging PV converter technology," IEEE Industrial Electronics Magazine, vol. 9, no 1, pp. 47-61, 2015.

[2] R. Dabou, et al, "Monitoring and performance analysis of grid connected photovoltaic under different climatic conditions in south Algeria," Energy Conversion and Management, vol. 130, pp. 200-206, December 2016.

[3] Sanjeev, K, Anil, K., Piush, K., "Avoiding Complex and Nonlinear Behaviour of Multilevel Power Inverter," International Journal of Innovative Technology and Exploring Engineering (IJITEE), vol. 9, no4, pp. 1-11, 2020.

[4] M. Louzazni, E. Aroudam, and H. Yatimi., "Modeling and simulation of a solar power source for a clean energy without pollution," International Journal of Electrical and Computer Engineering (IJECE), vol. 3, pp. 568-576, Aug. 2017.

[5] Shikha.G, Omveer.S, and M. A. Ansari, "Maximum power point tracking techniques for photovoltaic systems: A reveiw," in Advanced in Signal Processing and Communication, vol. 526, pp. 455-465, 2018

[6] S. Essaghir, M. Benchagra, and N. El Barbri, "Power factor control of a photovoltaic system connected to grid under load variation," in 2017 International Conference on Electrical and Information Technologies (ICEIT), pp. 17, 2017.

[7] S. Essaghir, M. Benchagra, and N. El Barbri, "Comparison between PI and PR Current Controllers of a GridConnected Photovoltaic System under Load Variation," International Journal of Power Electronics and Drive System (IJPEDS), vol. 9, no. 3, pp. 1311-1320, 2018.

[8] D. Zammit, C.S. Staines, M. Apap, "Comparison between PI and PR current controllers in grid connected PV Inverters," World Academy of Science, Engineering and Technology International Journal of Electrical, Computer, Energetic, Electronic and Communication Engineering, vol. 8, no. 2, pp. 221-226, 2014.

[9] M. R. Mojallizadeh, M. A. Badamchizadeh, "Second-order fuzzy sliding-mode control of photovoltaic power generation systems," Solar Energy, 149, pp. 332-340, 2017.

[10] A. D. Martin, et al., "Backstepping control of smart grid-connected distributed photovoltaic power supplies for telecom equipment," IEEE Transactions on Energy Conversion, vol. 30, no 4, pp. 1496-1504, 2015.

[11] J. Yu, P. Shi, et al, "Neural network based adaptive dynamic surface control for permanent magnet synchronous motors," IEEE Transactions on Neural Networks and Learning Systems, vol. 26, no 3, pp. 640-645, 2015.

[12] M.Yahiaoui, A. Kechich, and I. Bouserhane, "Adaptive sliding mode controlof PLMSM drive," International Journal of Power Electronics and Drive System (IJPEDS), vol. 8 no. 2, pp. 639-646, 2017.

[13] M. B. Delghavi, S. Shoja-Majidabad and A. Yazdani, "Fractional-order sliding-mode control of islanded distributed energy resource systems," IEEE Transactions on Sustainable Energy, vol. 7, no. 4, pp. 1482-1491, 2016.

[14] S. Golzari, F. Rashidi, and H. Feshki Farahani, "A Lyapunov function based model predictive control for three phase grid connected photovoltaic converters," Solar Energy, vol. 181, pp. 222-233, 2019.

[15] M. Louzazni, and E. Aroudam, "Linearizing and control of a three- phase photovoltaic system with feedback method and intelligent control in state-space," Transactions on Electrical and Electronic Materials, vol. 15, no. 6, pp. 297-304, 2014.

[16] V.Nandan Lal, S. N. Singh, "Control and performance analysis of a single stage utility scale grid Connected PV system," IEEE Systems Journal, vol. 11, no. 3, pp. 1601-1611, 2017. 
[17] M. Fakhfakh, Y. Cooren, A. Sallem, M. Loulou, P. Siarry "Analog circuit design optimization through the particle swarm optimization technique," Analog Integrated Circuits and Signal Processing, vol. 63, no. 1, pp. 71-82, 2009.

[18] T. Laagoubi, M. Bouzi, M. Benchagra, "MPPT \& power factor control for grid connected PV Systems with fuzzy logic controllers," International Journal of Power Electronics and System (IJPEDS), vol. 9, no. 1, pp. 105-113, 2018.

[19] S. Pendem, and S. Mikkili, "Modeling, Simulation and performance analysis of solar PV array configurations (series, series-parallel and honey-comb) to extract maximum power under partial shading conditions," Energy Reports, vol. 4, pp. 274-287, 2018.

[20] Yanfeng S., Huai W., Zian Q., "Modelling and control of dc-de converters," in Control of Power Electronic Converters and System, Academic Press, pp.69-92, 2018.

[21] R. Ingudam, and R. Nayak, "Modelling and performance analysis of DC-DC converters for PV grid connected system," International Journal of Science, Engineering and Technology Research, vol. 4, no. 5, pp. 1378-1390, 2015.

[22] JT. Martínez, et al., "Dynamic model of a grid-connected three-phase inverter with slope voltage control," IECON 2015 - 41st Annual Conference of the IEEE Industrial Electronics Society, pp. 001228-001233, 2015.

[23] A.H. Mollah, G.K. panda, and P.K Saha, "Three phase grid connected photovoltaic system with maximum power point tracking," International Journal of Advanced Research in Electrical, Electronics and Instrumentation Engineering, vol. 4, no. 5, pp. 4637- 4647, May 2015.

[24] N. Khaldi, et al., "Experimental Test Bench of Photovoltaic Systems using Backstepping MPPT Algorithm," International Journal of Renewable Energy Research, vol. 7, no. 2, pp. 815-824, 2017.

[25] R. Putri, et al., "Tuning PI controller based on multiobjective optimization approaches for speed control of PMSG wind turbine," International Review of Automatic Control, vol. 8, no. 4, pp. 315-321, 2015.

[26] M.Ghorbani, A. Mosallanejad, S. Mohamadian, "A new method to point of common coupling voltage control in distribution grid-connected photovoltaic systems," International Transactions on Electrical System, vol. 28, no. 2, pp.1-16, 2017.

[27] S. Roy, A. Malkhandi, "Modeling of 5kW single phase grid tied solar photovoltaic system," 2016 International Conference on Computer, Electrical \& Communication Engineering (ICCECE), pp. 1-8, 2016.

\section{BIOGRAPHIES OF AUTHORS}

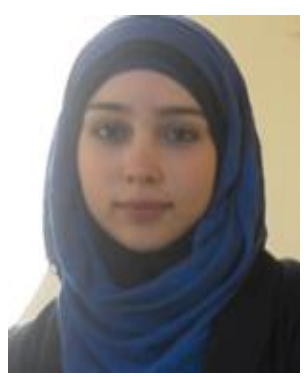

Salma Zouga was born in Meknes, Morocco, on October 02,1993. She received the engineering degree in electrical engineering from the National School of Applied Sciences of Oujda, University of Mohamed 1st Oujda in 2016. She is currently preparing her PhD in the field of electrical engineering at the National School of Applied Sciences of Khouribga, ISERT laboratory, University Sultan Moulay Slimane of Beni Mellal, under the supervision of the prof. M. Benchagra and Prof. A. Ailane

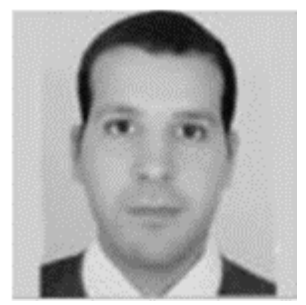

Mohamed Benchagra, was born in Beni-Mellal, Morocco, in 1982.He received the $\mathrm{Ph}$. D Mohamed V, Rabat, Morocco, in 2013. He is currently an Assistant Professor at the Technology High School (EST) Sultan Moulay Slimane University, Morocco. His research interests are electric machines, power electronics, power systems and renewable energy. Dr. Benchagra is a member of the IEEE

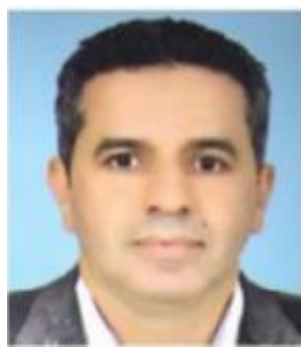

Abdellah Ailane is a university professor at the ENSA School of engineering in Khouribga, Morocco, qualified to direct researchs, has obtained his diploma in electrical engineering at the normal school of Mohammedia ENSET in 1995, then began advanced studies 'DESA' in automatic control at the ENSEM school in 2007. He obtained his doctorate in 2014 at the university Hassan 2 of Casablanca in control systems. Its research focusses on nonlinear control of industrial processes 